\title{
Influence of delayed cooling on quality of bell pepper (Capsicum annuum L.) stored in a controlled chamber
}

\author{
Md. Shaha Nur Kabiri,2, Milon Chowdhury', Wang-Hee Lee', Yong-Soo Hwang1, Seong-In Cho³, Sun-Ok Chung ${ }^{1 *}$ \\ ${ }^{1}$ College of Agriculture and Life Sciences, Chungnam National University, Daejeon, 34134, Republic of Korea, ${ }^{2}$ Faculty of Engineering, Hajee \\ Mohammad Danesh Science and Technology University, Dinajpur, 5200, Bangladesh, ${ }^{3}$ College of Agriculture and Life Sciences, Seoul \\ National University, Seoul, 08826, Republic of Korea
}

\section{A B S T R A C T}

\begin{abstract}
Improper postharvest handling, including delaying cooling, is a big concern for maintaining the freshness of fruit and vegetables in the postharvest supply chain. The objective of this study was to investigate the influence of short delays in cooling on some important quality parameters such as physiological weight loss, firmness, total soluble solids (TSS), and color $\left(L^{*}, h^{\circ}\right.$, and $\left.C^{*}\right)$ values of bell peppers stored in a controlled chamber. Bell peppers treated with three different treatments showed a gradual physiological weight loss of $1.46 \%, 3.18 \%$, and $3.14 \%$ after a storage period of 15 days with: immediate storage (IS) after harvest in a controlled chamber, delaying storage (DS), leaving bell pepper without cover for one day, and under cover (DSC) separately in a greenhouse and then storing them in the controlled chamber, respectively. Over the storage period, slower firmness reduction (19.88\%) of the IS treated bell peppers was observed compared to other bell pepper samples with delayed cooling. Bell peppers that underwent IS treatment showed lower changes in TSS ( $\left.{ }^{\circ} \mathrm{Bx}\right)$ values (6.89 to 7.24) compared to other treatments during the storage period. Fewer changes in color $\left(L^{*}, h^{\circ}\right.$, and $\left.C^{*}\right)$ values were found with IS treated bell peppers. Overall changes in the assessed quality parameters of bell pepper samples were slower with IS treatment than delayed cooling treatments throughout the storage period. This study provides significant information on the handling of harvested bell pepper in a favorable environment before transportation to processing and storage centers.
\end{abstract}

Keywords: Cooling delay; Bell pepper; Post-harvest handling; Quality parameter; Storage

\section{INTRODUCTION}

Bell pepper (Capsicum annum $\mathrm{L}$.) is a balanced source of most essential nutrients, has rich sources of carotenoids and important antioxidants, and is rich in flavonoids and phytochemicals (Curl, 1962, 1964; Matus et al., 1991; Marin et al., 2004; Maria et al., 2010; Gandolfi et al., 2018). Recently, the cultivation area and yield of bell pepper have been increasing as it is a rich source of functional values for anti-aging and healthy beauty foods, with possible links to the prevention of certain types of cancers and diseases (Vanderslice et al., 1990; Simonne et al., 1997), hence contributing to the increased global trade of bell pepper (Topuz et al., 2009). However, similar to other agricultural produce, bell pepper is highly perishable and susceptible to quality deterioration; therefore, specific postharvest handling is required (O’Donoghue et al., 2017).

Fresh produce should be available with good quality to meet consumer demand; therefore, producers and consumers place a lot of importance on the retention of their quality attributes during handling and storage (Sigge et al., 2001). Peppers rapidly lose water after harvest, which contributes to a major quality problem and has a negative impact on pepper freshness during shipment, storage and subsequent marketing (Lownds et al., 1993). With improper post-harvest management, the quality of bell pepper changes very fast and it spoils after harvest due to its perishable nature. Therefore, the post-harvest environment before storage in an environment-controlled facility is critical for maintaining the quality of bell pepper at the time of consumption.

Temperature and humidity have the strongest influence on the postharvest quality and extending the shelf life of fruits and vegetables (Tano et al., 2007). Proper temperature management between the period of harvesting and consumption has been found to be the most effective way to maintain quality (Arah et al., 2015). Cooling delays cause reduced quality of fruits and vegetables due to high rates

\footnotetext{
${ }^{*}$ Corresponding author:

Sun-Ok Chung, College of Agriculture and Life Sciences, Chungnam National University, Daejeon, 34134, Republic of Korea.

E-mail: sochung@cnu.ac.kr
}

Received: 21 January 2019; Accepted: 22 March 2019 
of respiration and associated normal metabolism, fostering water losses, and increasing decay development (Paull, 1999; Thompson et al., 2001). After harvesting, even a short cooling delay for some fresh fruits can result in quantitative and qualitative losses up to $10 \%$ during marketing (Kader and Rolle, 2004). Nunes et al. (1995) found that 6 or 8-hr delay at $30^{\circ} \mathrm{C}$ before storing strawberries for 1 week at $1^{\circ} \mathrm{C}$ and 1 day at $20^{\circ} \mathrm{C}$ resulted overall quality losses compared to the fruits that were immediately cooled. Cantwell and Thangaiah (2012) reported average weight losses of 0.4 and $0.75 \%$ per hour for bell peppers during delays at 25 and $37^{\circ} \mathrm{C}$, respectively, and also resulted in losses of fruit firmness, gloss, and visual quality. On the other hand, at very high relative humidity, harvested fruits and vegetables maintain their appearance, freshness, nutritional quality, and shelf life.

Around the world, postharvest quality and shelf-life extension of horticultural produce to get maximum returns have always been a major concern, hence, postharvest handling and storage environment needs to be improved for better access to domestic and export markets (Simmons et al., 1997; Hameed et al., 2013). Postharvest handling of bell pepper such as immediate cooling after harvest or delays in cooling while leaving bell pepper inside a greenhouse for a short period of time are important factors for producing high quality produce. Delays in cooling of bell pepper after harvest may result in overall quality loss, not only during storage, but also even in processing in general.

Post-harvest losses of vegetables due to their highly perishable nature are a major concern for producers and processors (El-Ramady et al., 2015; Chitravathi et al., 2015; Shim et al., 2016). Some loss is inevitable, and the extent of postharvest losses varies depending on the produce, handling procedure, storage, and environmental conditions (Ramaswamy, 2015; Lim et al., 2016). The quality of the produce should be maintained through all phrases from field production to consumption. Therefore, proper postharvest handling of bell pepper is crucial for quality produce either consumed as a fresh commodity or processed (Bosland and Votava, 2012).

Recently, numerous researchers have reported postharvest quality losses in bell pepper (Tsegay et al., 2013; D1'azPe'rez, 2013; Belović et al., 2014; Cheema et al., 2018). Some researchers reported the effect of postharvest and packaging treatments on the storage quality of bell peppers (Cuadra-Crespo and del Amor, 2010; Ilić et al., 2012; Singh et al., 2014; Choi et al., 2017). Few reports, however, have focused on the effects of short-time cooling delays on the quality of harvested bell pepper. In addition, conventionally, most of growers and produce handlers keep harvested bell pepper unattended in a greenhouse for about half a day or one day before transportation to a processing and storage center. The ambient environment before storing bell pepper could have some effects on the quality and shelf life of bell pepper. Therefore, it is important to explore the influence of cooling delays on the postharvest quality of bell pepper.

Weight, firmness, total soluble solids, and color are important quality factors of fruits and vegetables (Kader et al., 1977; Satyan and Patwardhan, 1983) that are critical to consumer acceptance and market success (Barrett et al., 2010), and could be maintained with appropriate postharvest handling procedures. Therefore, the objective of this study was to investigate the influence of short cooling delays on physiological weight, firmness, TSS content, and color $\left(L^{*}, B^{\circ}\right.$, and $\left.C^{*}\right)$ values of bell pepper, such as the immediate storage in a controlled chamber after harvest, delaying storage leaving bell pepper with and without cover for one day separately in a greenhouse and then storing them in a controlled chamber.

\section{MATERIAL AND METHODS}

\section{Bell pepper samples and delayed cooling treatments}

"Ferrari" variety bell peppers were grown in the middle part of Republic of Korea and harvested in May 2016 with an average height and width of $11 \pm 1.6 \mathrm{~cm}$ and $8 \pm 1.2 \mathrm{~cm}$, respectively. The bell pepper samples were evaluated under three different treatments: "immediate storage of bell pepper after harvest (IS)" in the controlled chamber (i.e., without any cooling delay), storage in the controlled chamber after "delayed storage leaving bell pepper without cover for one day (DS)" in a greenhouse, and storage in the controlled chamber after "delayed storage leaving bell pepper under cover with a greenhouse shade cloth of $1.0 \mathrm{~mm}$ thickness (DSC)" in a greenhouse (i.e., treatments with cooling delayed for 24 hours).

The treatments were performed in separate spaces in the controlled chamber and greenhouse with dimensions of $6.5 \mathrm{~m} \times 4.5 \mathrm{~m} \times 3.0 \mathrm{~m}$ and $7.5 \mathrm{~m} \times 5.5 \mathrm{~m} \times 3.5 \mathrm{~m}$, respectively in the Department of Bisosystems Engineering, Chungnam National University, Daejeon, Republic of Korea. One group of bell pepper samples was stored inside the controlled chamber immediately after harvest (day 0), maintaining the temperature and humidity at $10 \pm 1^{\circ} \mathrm{C}$ and $90 \pm 3 \%$, respectively. Two other groups of bell pepper samples were put separately inside a greenhouse with and without cover on the same day (Fig. 1). Temperature and humidity conditions inside the greenhouse were continuously monitored using four sensor nodes composed of temperature and humidity sensors (model: AM2315, Aosong Electronics Co., Ltd., Guangzhou, China), placed outside of the greenhouse, inside the greenhouse, and in 


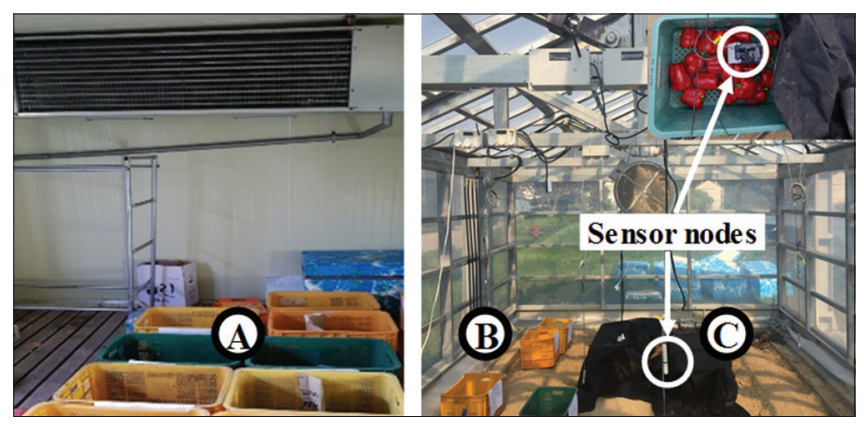

Fig 1. Photographs of delayed cooling treatments: A. immediate storage (IS) after harvest in a controlled chamber; B. delaying storage (DS) leaving bell pepper without cover for one day and $\mathrm{C}$. delaying storage leaving bell pepper under cover (DSC) for one day, separately in a greenhouse and then storing them in the controlled chamber (inset photo- bell peppers).

the bell pepper storage boxes (covered and uncovered) during cooling delayed for 24 hours in the greenhouse.

During this 24-hr delayed cooling, the temperature and humidity inside the greenhouse was $28 \sim 38^{\circ} \mathrm{C}$ and $60 \sim 85 \%$, respectively, while temperature and humidity outside of the greenhouse was $18 \sim 28^{\circ} \mathrm{C}$ and $55 \sim 75 \%$, respectively. During this delayed cooling period inside the greenhouse, the temperature and humidity inside the bell pepper box without cover was $29 \sim 39^{\circ} \mathrm{C}$ and $60 \sim 80 \%$, and inside the bell pepper box with cover was $26 \sim 36^{\circ} \mathrm{C}$ and $65 \sim 85 \%$, respectively. Postharvest recommendations suggest that gas combination in a storage environment plays an important role in extending the storage life of bell pepper; therefore, the optimal atmosphere conditions for storage of bell pepper combining $2-5 \% \mathrm{O}_{2}$ and $2-5 \% \mathrm{CO}_{2}$ have been suggested to inhibit deterioration with storage time (Kader, 1983; Cantwell, 2001). The quality parameters of the bell pepper samples were measured on harvest day (day 0 ) and were immediately put in the three treatments. One day later, the bell pepper samples treated inside the greenhouse with and without cover were put back in the controlled chamber. Thereafter, all bell pepper samples were stored continuously in the controlled chamber and measurements of the quality parameters of the stored bell pepper were taken during the storage period at 5, 10, and 15 days.

\section{Experiment design and statistical analysis}

The bell peppers were assigned to the IS, DS, and DSC storage environments and 30 samples were taken for each storage treatment and three replications were taken for each of the storage treatments. There were 90 samples for each treatment, and a total of 360 bell peppers were taken for evaluating quality parameters such as physiological weight loss, firmness, total soluble solids (TSS), and color $\left(L^{*}, b^{\circ}\right.$, and $\left.C^{*}\right)$ values at $0,5,10$, and 15 days of storage. Significance tests were made by analysis of variance (ANOVA), taking a completely randomized design with subsampling combined over the storage period with SAS software (version 9; SAS Corporation, Cary, NC, USA), and the significant differences were assessed at the $5 \%$ level of significance. The factors considered in the statistical analysis of the data were delayed cooling treatments, storage time, replication, and observation. In addition, differences among means were determined by Duncan's multiple range test at the $5 \%$ significance level to identify similar groups among the delayed cooling treatments and quality parameters of bell pepper throughout the storage period.

Various regression approaches were performed to predict changes in quality parameters during the storage period of the bell pepper treated with the three treatments. Bell peppers treated under different treatments were considered independent variables and quality parameters as dependent variables. After simple linear regression, some nonlinear transformations such as logarithm $(\ln (x))$, exponent $\left(e^{x}\right)$, power $\left(k x^{\prime \prime}\right)$, and polynomial $(P(x))$ were used to analyze the changes in quality parameters of stored bell pepper, and the level of significance of each equation was also identified. The coefficient of determination $\left(R^{2}\right)$ values were considered goodness of fit for the regression models used to select the best model for describing the changes in quality parameters during the storage period.

\section{Measurement of quality parameters Physiological weight loss (PWL)}

The physiological weight loss was evaluated by weighing individual bell pepper before and after placing them into each storage. The difference between initial and final weight on the day of observation of the fruit was considered as total physiological weight loss during each storage interval and expressed as percentages (Gharezi et al., 2012).

PWL $(\%)=($ Initial weight-Final weight on the day of observation $) /($ Initial weight $) \times 100$

\section{Firmness}

The firmness of the bell pepper was determined using a penetrometer (model: TMS-Pro, Food Technology Corporation, Sterling, Virginia, USA) by measuring the force required for making a predetermined pierce using a standard probe. The bell peppers were compressed by the probe at a $5 \mathrm{~mm}$ penetration depth using a conical plate at a speed of $50 \mathrm{~mm} / \mathrm{min}$ (Choi et al., 2011).

\section{Total soluble solids (TSS)}

Bell pepper samples were randomly taken and wrapped with four layers of cheesecloth, and juice was extracted using a juice extractor (model: FruX80, Goojung Engineering Co. Ltd., Seoul, Korea). The sample was thoroughly mixed and the TSS content was examined using a digital refractometer 
(model: PR-32a, Atago Co. Ltd., Tokyo, Japan) and the values were expressed as Brix $\left({ }^{\circ} \mathrm{Bx}\right)$.

\section{Color}

The color of bell pepper plays an important role in consumer acceptance. The color $\left(L^{*}, a^{*}\right.$, and $\left.b^{*}\right)$ values of bell pepper were measured at 0 day and during each storage interval using a colorimeter (model: CR-400; Konica Minolta Inc., Tokyo, Japan). The color values were measured according to the procedure of Khairi et al. (2015). The hue angles $\left(b^{\circ}\right)$ and chroma $\left(C^{*}\right)$ values were calculated according to the procedure used by Topuz et al. (2009).

\section{RESULTS AND DISCUSSION}

\section{Physiological weight loss (PWL)}

The effects of delayed cooling treatments on physiological weight loss of bell pepper with storage periods are shown in Fig. 2a. In this study, the physiological weight loss value increased during the evaluation period in all bell pepper samples treated under the three treatments. Among the bell pepper samples, DS and DSC treated samples showed a similar trend in physiological weight loss throughout the storage period. After the storage period, physiological weight loss of the bell pepper with IS treatment was found to be the lowest at $1.46 \%$, while the physiological weight loss of samples with delayed cooling under DS and DSC treatment increased by $3.18 \%$ and $3.14 \%$, respectively.

The analysis of variance of the bell pepper quality parameters with delayed cooling treatments and storage days as factors is presented in Table. 1. Significant $(p<0.05)$ changes in all quality parameters of stored bell pepper among the three different treatments and between the storage days are presented in Table. 2 and 3. The statistical analysis showed that the effect of delayed cooling treatments as well as storage period on the physiological weight loss of bell pepper was found to be significant at the $1 \%$ level of significance. $R^{2}$ and coefficient of variation (CV) values for the physiological weight loss parameter were found to be low. Experimental data on physiological weight loss with storage periods under the three different storage treatments fitted polynomial models with goodness of fit $\mathrm{R}^{2}$ values of $0.96,0.99$, and 0.99 for IS, DS, and DSC treated bell pepper, respectively (Fig. 2a).

Increase of physiological weight loss of bell pepper with storage period is in agreement with the findings of several researchers. Znidarcic et al. (2010) observed progressive weight loss of bell pepper fruit throughout the storage period due to the loss of water through transpiration, reducing market value and consumer acceptability. Nyanjage et al. (2005) found losses in the weight of sweet pepper throughout a storage period of 25 days tested with different packages and stored at various temperatures. Bell peppers are very susceptible to water loss, and reducing this water loss is the priority during storage (O'Donoghue et al., 2017). The variable temperature environment may increase the rate of water loss, possibly by increasing the vapor pressure deficit between the tissue and the surrounding air, leading to the enhancement of transpiration (BenYehoshua and Rodov, 2003). Shafiee et al. (2010) reported that loss of weight in strawberry fruit is due to metabolic activity, respiration, and transpiration. Delayed cooling of bell pepper samples for 24 hours stored with and without cover in a greenhouse showed more significant physiological weight loss than bell peppers stored in a controlled chamber immediately after harvest, leading to negative effects on its appearance and acceptability on a consumer level.

\section{Firmness}

A continuous and gradual decline in the firmness of bell pepper was observed in all treatments throughout the storage period (Fig. 2b). The statistical analysis indicates that the firmness values of bell pepper were found to be significantly affected ( $1 \%$ level) by the delayed cooling treatments (Table. 1). The $\mathrm{R}^{2}$ and $\mathrm{CV}$ values for the firmness change parameter in this study were found to be low. Although significant differences in firmness losses were observed among all treated bell pepper samples throughout the storage period, the firmness losses were slower in IS treated bell pepper samples $(19.86 \%)$ compared to DS $(24.76 \%)$ and DSC $(21.77 \%)$ treated bell pepper samples by the end of the storage period (Table 2).

Similar to our findings, a continuous and gradual decrease in fruit firmness was observed by Cheema et al. (2018) during prolonged storage of bell peppers under different postharvest treatments. This firmness decrease of fruit throughout the storage periods is due to a high respiration rate and weight loss (Cantwell et al., 2009; Lahay et al., 2013). This study indicated that DSC treated bell pepper fruit showed lower changes than DS, which could be due to the cover reducing the air temperature inside the bell pepper box (Mahmood et al., 2018), and immediate storage after harvesting bell pepper could maintain better firmness than delayed cooling of bell pepper. Data on firmness changes of bell pepper samples over storage time under the three treatments fitted polynomial models with $\mathrm{R}^{2}$ values of $0.98,0.97$, and 0.96 for IS, DS, and DSC treated bell pepper, respectively (Fig. 2b).

\section{Total soluble solids (TSS)}

The changes in TSS values of bell pepper that underwent three different treatments during the storage period with their fitted curves are presented in Fig. 2c. There was a significant $(\mathrm{P}<0.05)$ gradual increase in TSS throughout 


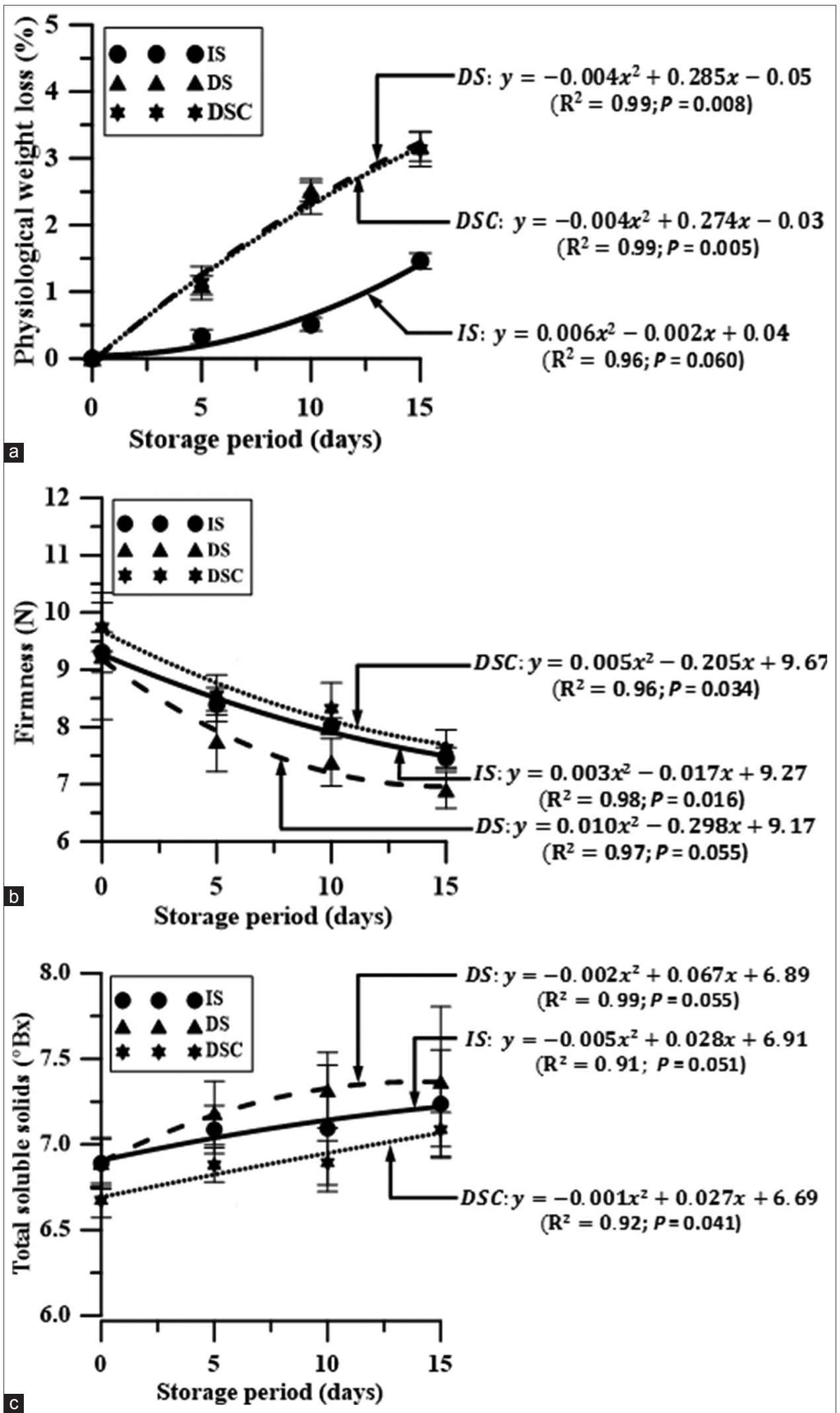

Fig 2. Changes in physiological weight loss (a), firmness (b), and TSS content (c) of bell peppers during 15 days of storage under three different delayed cooling treatments (IS, DS, and DSC).

the storage period, but the lowest increase was recorded from 6.89 to $7.24^{\circ} \mathrm{Bx}$ for IS treated bell pepper compared to treated bell pepper in DS and DSC conditions. A higher increase in TSS was observed for DS treated samples. 
Table 1: Summary of ANOVA of bell pepper quality parameters stored under three different delayed cooling treatments and storage days as factors; $p$ values indicate significance at $\alpha<0.05$

\begin{tabular}{|c|c|c|c|c|c|c|c|}
\hline \multirow[t]{2}{*}{ Source } & \multirow[t]{2}{*}{ DF } & \multicolumn{6}{|c|}{$p$-value } \\
\hline & & Weight & TSS & Firmness & $L^{*}$ & $h^{\circ}$ & $C^{\star}$ \\
\hline Model & 11 & $<0.0001$ & 0.027 & $<0.0001$ & $<0.0001$ & $<0.0001$ & 0.065 \\
\hline Treatments & 2 & $<0.0001$ & 0.009 & 0.003 & 0.084 & 0.084 & 0.016 \\
\hline Storage period & 3 & $<0.0001$ & 0.006 & $<0.0001$ & $<0.0001$ & $<0.0001$ & 0.026 \\
\hline Error & 24 & & & & & & \\
\hline Total & 35 & & & & & & \\
\hline$R^{2}$ & & 0.98 & 0.74 & 0.83 & 0.82 & 0.81 & 0.78 \\
\hline CV & & 11.48 & 3.21 & 5.73 & 2.12 & 5.75 & 3.63 \\
\hline RMSE & & 0.15 & 0.23 & 0.47 & 0.68 & 1.44 & 1.26 \\
\hline
\end{tabular}

Table 2: Influence of delayed cooling treatments and storage duration on changes in physiological weight loss, TSS, and firmness parameters of bell pepper for a storage period of 15 days

\begin{tabular}{llcccc}
\hline Quality parameters & Treatments & \multicolumn{3}{c}{ Storage period (day) } \\
\cline { 3 - 5 } & & $\mathbf{0}$ & $\mathbf{5}$ & 10 & 10 \\
\hline Physiological weight loss (\%) & IS & $0^{\mathrm{d}}$ & $0.33^{\mathrm{c}}( \pm 0.11)$ & $0.51^{\mathrm{b}}( \pm 0.10)$ & $1.46^{\mathrm{a}}( \pm 0.12)$ \\
& DS & $0^{\mathrm{d}}$ & $1.09^{\mathrm{c}}( \pm 0.10)$ & $2.52^{\mathrm{b}}( \pm 0.17)$ & $3.18^{\mathrm{a}}( \pm 0.22)$ \\
Firmness (N) & DSC & $0^{\mathrm{d}}$ & $1.13^{\mathrm{c}}( \pm 0.14)$ & $2.39^{\mathrm{b}}( \pm 0.23)$ & $3.12^{\mathrm{a}}( \pm 0.26)$ \\
& IS & $9.31^{\mathrm{a}}( \pm 0.35)$ & $8.39^{\mathrm{b}}( \pm 0.29)$ & $8.02^{\mathrm{b}}( \pm 0.13)$ & $7.45^{\mathrm{c}}( \pm 0.18)$ \\
& DS & $9.24^{\mathrm{a}}( \pm 1.10)$ & $7.75^{\mathrm{b}}( \pm 0.53)$ & $7.38^{\mathrm{b}}( \pm 0.42)$ & $6.90^{\mathrm{b}}( \pm 0.32)$ \\
Total soluble solids ( $\left.{ }^{\circ} \mathrm{Bx}\right)$ & DSC & $9.74^{\mathrm{a}}( \pm 0.43)$ & $8.56^{\mathrm{b}}( \pm 0.35)$ & $8.32^{\mathrm{bc}}( \pm 0.45)$ & $7.62^{\mathrm{c}}( \pm 0.33)$ \\
& IS & $6.89^{\mathrm{a}}( \pm 0.15)$ & $7.08^{\mathrm{a}}( \pm 0.14)$ & $7.09^{\mathrm{a}}( \pm 0.36)$ & $7.24^{\mathrm{a}}( \pm 0.32)$ \\
& DS & $6.89^{\mathrm{a}}( \pm 0.14)$ & $7.18^{\mathrm{a}}( \pm 0.18)$ & $7.32^{\mathrm{a}}( \pm 0.22)$ & $7.36^{\mathrm{a}}( \pm 0.44)$ \\
& DSC & $6.67^{\mathrm{c}}( \pm 0.11)$ & $6.88^{\mathrm{b}}( \pm 0.10)$ & $6.89^{\mathrm{b}}( \pm 0.13)$ & $7.08^{\mathrm{a}}( \pm 0.10)$ \\
\hline
\end{tabular}

For each treatment, means $( \pm S D)$ within a row with different lowercase letters are statistically different $(p<0.05)$ among storage days

Table 3: Influence of delayed cooling treatments and storage duration on changes in color $\left(L^{*}, h^{\circ}\right.$, and $\left.C^{*}\right)$ values of bell pepper for a storage period of 15 days

\begin{tabular}{llcccc}
\hline $\begin{array}{l}\text { Color } \\
\text { parameters }\end{array}$ & Treatments & \multicolumn{4}{c}{ Storage period (day) } \\
\cline { 2 - 6 } & & $\mathbf{0}$ & $\mathbf{5}$ & \multicolumn{1}{c}{$\mathbf{1 0}$} & $\mathbf{1 0}$ \\
\hline$L^{*}$ & IS & $33.55^{\mathrm{a}}( \pm 0.45)$ & $32.65^{\mathrm{a}}( \pm 0.34)$ & $31.29^{\mathrm{b}}( \pm 0.34)$ & $30.89^{\mathrm{b}}( \pm 0.61)$ \\
& DS & $33.42^{\mathrm{a}}( \pm 0.82)$ & $31.38^{\mathrm{b}}( \pm 1.12)$ & $31.95^{\mathrm{ab}}( \pm 0.53)$ & $30.18^{\mathrm{b}}( \pm 1.12)$ \\
& DSC & $34.46^{\mathrm{a}}( \pm 0.45)$ & $32.30^{\mathrm{b}}( \pm 0.34)$ & $31.40^{\mathrm{c}}( \pm 0.34)$ & $31.37^{\mathrm{c}}( \pm 0.61)$ \\
$h^{\circ}$ & IS & $28.97^{\mathrm{a}}( \pm 0.04)$ & $26.39^{\mathrm{b}}( \pm 1.08)$ & $24.40^{\mathrm{bc}}( \pm 0.73)$ & $23.46^{\mathrm{c}}( \pm 0.84)$ \\
& DS & $28.31^{\mathrm{a}}( \pm 2.48)$ & $25.16^{\mathrm{b}}( \pm 1.71)$ & $22.69^{\mathrm{bc}}( \pm 0.86)$ & $21.58^{\mathrm{c}}( \pm 0.85)$ \\
& DSC & $28.44^{\mathrm{a}}( \pm 1.28)$ & $25.47^{\mathrm{b}}( \pm 1.46)$ & $23.89^{\mathrm{bc}}( \pm 1.45)$ & $22.18^{\mathrm{c}}( \pm 1.46)$ \\
$C^{*}$ & IS & $34.97^{\mathrm{a}}( \pm 0.54)$ & $35.37^{\mathrm{a}}( \pm 0.62)$ & $35.62^{\mathrm{a}}( \pm 0.66)$ & $36.08^{\mathrm{a}}( \pm 0.63)$ \\
& DS & $32.67^{\mathrm{c}}( \pm 0.55)$ & $33.29^{\mathrm{bc}}( \pm 0.69)$ & $34.56^{\mathrm{ab}}( \pm 0.99)$ & $35.15^{\mathrm{a}}( \pm 0.99)$ \\
& DSC & $34.05^{\mathrm{a}}( \pm 1.01)$ & $34.90^{\mathrm{a}}( \pm 0.57)$ & $34.81^{\mathrm{a}}( \pm 2.66)$ & $36.20^{\mathrm{a}}( \pm 2.32)$ \\
\hline
\end{tabular}

For each treatment, means $( \pm S D)$ within a row with different lowercase letters are statistically different $(p<0.05)$ among storage days

The analysis of variance indicates that TSS of bell pepper vary significantly (at 5\% level) over the delayed cooling treatments as well as period of storage. $\mathrm{R}^{2}$ and $\mathrm{CV}$ values for change in TSS contents during storage period was found to be low (Table 1).

Similar trends in changes of TSS values were reported by Bagnazari et al. (2018) during the postharvest storage period of bell peppers with different pre-harvest treatments. The decrease in the TSS for IS treated bell pepper could be due to the slowing of respiration and metabolic activity, resulting in a slower change from carbohydrates to sugars (Ali et al., 2011). The increase in TSS for DSC treated samples was comparatively slower than for DS treated fruit, which could be due to the cover effects reducing greenhouse air temperature (Abdel-Ghany et al., 2015). The data obtained on changes in TSS values over storage time under the three storage treatments fitted polynomial models with $\mathrm{R}^{2}$ values of $0.91,0.99$, and 0.92 for IS, DS, and DSC treated bell pepper samples, respectively (Fig. 2c).

\section{Color}

Fig. 3 shows the changes in color $\left(L^{*}, b^{\circ}\right.$, and $\left.C^{*}\right)$ values of bell pepper throughout the storage duration with the three different treatments. During the storage period, a general decrease in the skin color of bell pepper was 


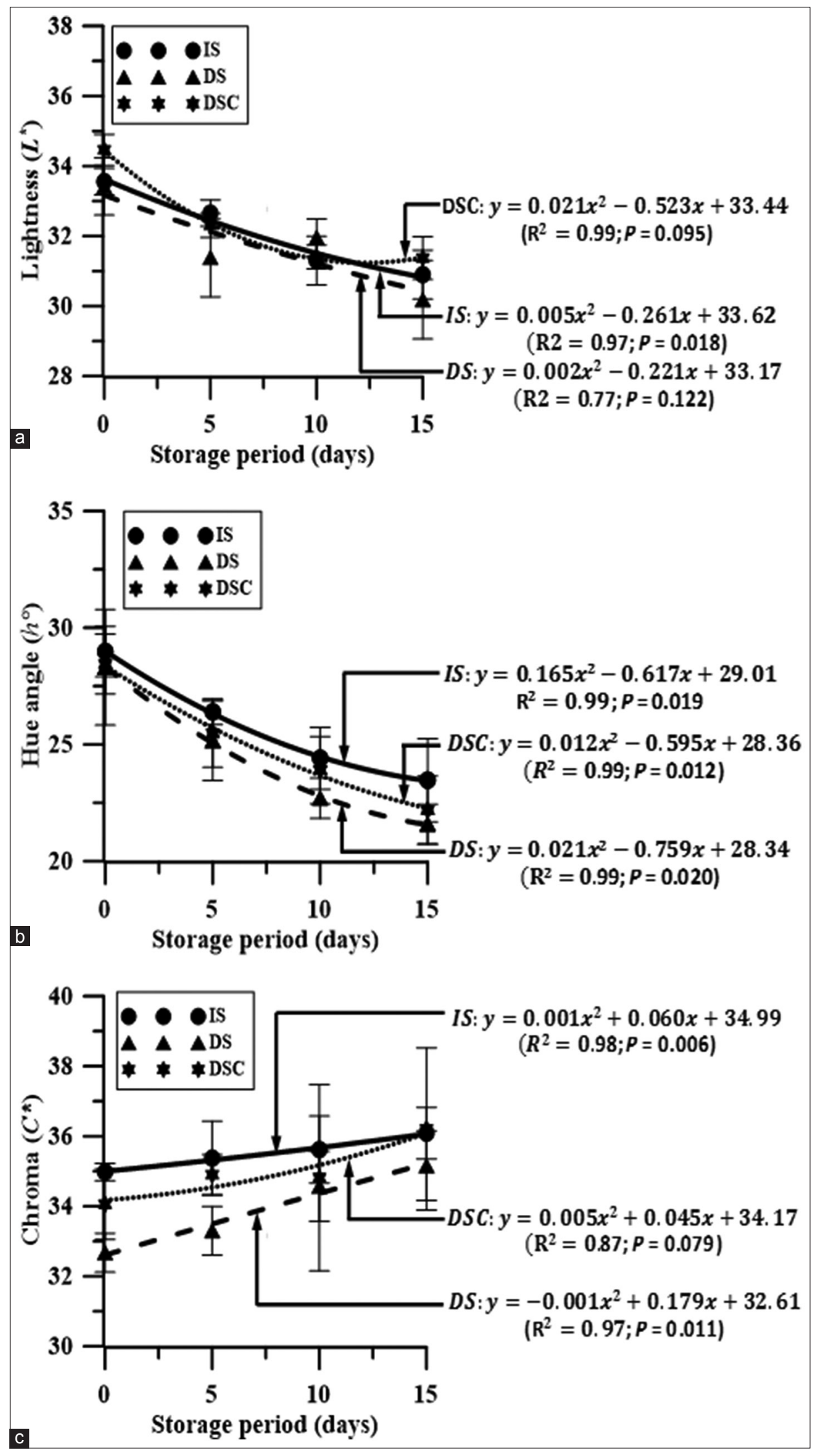

Fig 3. Changes in lightness (a), hue angle (b), and chroma (c) values of bell peppers during 15 days of storage under three different delayed cooling treatments (IS, DS, and DSC).

observed. There was significant variation (at the 1\% level of significance) in the color $\left(L^{*}\right)$ values of bell pepper fruits subjected to different delayed cooling treatments. The bell pepper samples stored under IS treatment showed 
slower changes in $L^{*}$ (33.55-30.89) values, indicating less browning compared to the other delayed cooling treated samples. A significant decrease in the $b^{\circ}$ value of all treated bell pepper was observed during the storage period. Less of a decrease in $h^{\circ}(28.97-23.46)$ values occurred for IS treated bell pepper samples compared to DS and DSC treated samples after 15 days of storage. The $C^{*}$ values were significantly different (at the 5\% level) and followed the same trend for all treated bell pepper samples (Table. 1). The lowest changes in $C^{*}$ values were observed from 34.97 to 36.08 for IS treated bell pepper samples compared to DS and DSC treated bell pepper samples after 15 days of storage (Table 3). Color change in fruit is associated with the ripening process and is one of the indications of physicochemical development stages (Renquist and Reid, 1998; Tigist et al., 2013). Srinivasa et al. (2006) observed fewer changes in $L^{*}$ values and a gradual decrease in hue angle during storage of bell peppers using eco-friendly films.

The color $\left(L^{*}, b^{\circ}\right.$, and $\left.C^{*}\right)$ values of bell pepper samples over the storage period under the three treatments were also analyzed by different linear and nonlinear regressions. The polynomial models were found to be the equations that best described the changes in color value $L^{*}$ during the storage period with $\mathrm{R}^{2}$ values of $0.97,0.77$, and 0.99 for IS, DS, and DSC treated bell pepper samples, respectively (Fig. 3a). Whereas the changes in $b^{\circ}$ values during the storage period were fitted with $\mathrm{R}^{2}$ values of $0.99,0.99$, and 0.99 for IS, DS, and DSC treated bell pepper samples, respectively (Fig. 3b), and the changes in $C^{*}$ values were fitted with $\mathrm{R}^{2}$ values of $0.98,0.97$, and 0.87 for IS, DS, and DSC treated bell pepper samples, respectively (Fig. 3c).

\section{CONCLUSIONS}

Bell pepper is one of the most important horticultural commodities and requires appropriate postharvest handling due to high susceptibility to quality deterioration. Delays between harvest and storage could results qualitative deterioration of bell pepper. Therefore, this study was aimed to investigate the effects of cooling delays before storage on some quality parameters of bell pepper stored in a controlled chamber $\left(10 \pm 1^{\circ} \mathrm{C}, 90 \pm 3 \%\right)$.

Three delayed cooling treatments, IS, DS, and DSC, were applied to the harvested bell pepper and physiological weight, firmness, TSS content, and color $\left(L^{*}, b^{\circ}\right.$, and $\left.C^{*}\right)$ values were measured for 15 days at 5 -day intervals. Overall changes of the IS treated bell pepper fruits were slower compared to other samples for the assessed quality parameters throughout the storage period. The quality parameters of DSC treated bell pepper remained better than DS treated samples due to the cover effects. Delayed cooling for 24 hours had significant negative effects on the quality parameters compared to the bell pepper stored in a controlled chamber immediately after harvest. The data of this research may indicate that bell pepper should be stored immediately after harvesting for better quality during storage. Therefore, a delay between harvest and cooling would be expected to persist at the consumer level.

This research revealed the impact of delayed cooling treatments on the quality parameters of bell pepper stored in a controlled chamber, so farmers should handle their harvested bell pepper in a controlled chamber before transportation to processing and storage centers. However, further studies with different cooling delay times (i.e., 0 to 72 hours) for different cultivars are needed to model the impact of delayed cooling on bell pepper before storage to controlled chamber. Studies on the impact of mechanical damages on bell pepper fruits during transportation from field to consumer chain would also be extended to investigate the total postharvest losses.

\section{ACKNOWLEDGEMENTS}

This work was supported by the Korea Institute of Planning and Evaluation for Technology in Food, Agriculture, Forestry and Fisheries (IPET) through the Advanced Production Technology Development Program, funded by the Ministry of Agriculture, Food and Rural Affairs (MAFRA) (Project No. 315009-03-1-WT011), Republic of Korea.

\section{Author's contributions}

Md. Shaha Nur Kabir and Milon Chowdhury performed the experiments. Md. Shaha Nur Kabir analyzed the data and wrote the manuscript. Sun-Ok Chung, Yong-Soo Hwang, and Seong-In Cho designed the experiments. Wang-Hee Lee, Sun-Ok Chung, Yong-Soo Hwang revised the manuscript. All authors read and approved the final manuscript.

\section{REFERENCES}

Abdel-Ghany, A. M., P. Picuno, I. M. Al-Helal, A. Alsadon, A. A. Ibrahim and M. R. Shady. 2015. Radiometric characterization, solar and thermal radiation in a greenhouse as affected by shading configuration in an arid climate. Energies. 8: 13928-13937.

Ali, A., M. T. M. Muhammad, K. Sijam and Y. Siddiqui. 2011. Effect of chitosan coating on the physicochemical characteristics of Eksotika II papaya (Carica papaya L.) fruit during cold storage. Food Chem. 124: 620-625.

Arah, I. K., H. Amaglo, E. K. Kumah and H. Ofori. 2015. Preharvest and postharvest factors affecting the quality and shelf life of harvested tomatoes: A mini review. Int. J. Agron. 2015: 1-6.

Bagnazari, M., M. Saidi, M. Mohammadi, O. Khademi and G. Nagaraja. 
2018. Pre-harvest $\mathrm{CaCl} 2$ and $\mathrm{GA} 3$ treatments improve postharvest quality of green bell peppers (Capsicum annum L.) during storage period. Sci. Hortic. 240: 258-267.

Barrett, D. M., J. C. Beaulieu and R. Shewfelt. 2010. Color, flavor, texture, and nutritional quality of fresh-cut fruits and vegetables: Desirable levels, instrumental and sensory measurement, and the effects of processing. Crit. Rev. Food Sci. 50: 369-389.

Belović, M. M., J. S. Mastilović and Ž. S. Kevrešan. 2014. Change of surface colour parameters during storage of paprika (Capsicum annuum L.). Food and Feed Res. 41: 85-92.

Ben-Yehoshua, S. and V. Rodov. 2003. Transpiration and water Stress. In: Bartz, J. A. and J. K. Brecht, (Eds.), Postharvest Physiology and Pathology of Vegetables, 2nd ed. Marcel Dekkar, New York, pp. 121-159.

Cantwell, P. W. and E. J. Votava. 2012. Peppers: Vegetable and Spice Capsicum (Crop Production Science in Horticulture 22), CAB International, Wallingford, UK, pp. 155-158.

Cantwell, M. 2001. Properties and Recommended Conditions for the Long-Term Storage of Fresh Fruits and Vegetables. Storage Recommendations, Department of Plant Sciences, University of California, Davis.

Cantwell, M., X. Nie and G. Hong. 2009. Impact of Storage Conditions on Grape Tomato Quality. In: Proceedings of the VI International Postharvest Symposium, Antalya, Turkey.

Cantwell, M. I. and A. Thangaiah. 2012. Acceptable cooling delays for selected warm season vegetables and melons. Acta Hortic. 934: 77-84.

Cheema, A., P. Padmanabhan, A. Amer, M. J. Parry, L. T. Lim, J. Subramanian and G. Paliyath. 2018. Postharvest hexanal vapor treatment delays ripening and enhances shelf life of greenhouse grown sweet bell pepper (Capsicum annum L.). Postharvest Biol. Technol. 136: 80-89.

Chitravathi, K., O. P. Chauhan and P. S. Raju. 2015. Influence of modified atmosphere packaging on shelf-life of green chillies (Capsicum annuum L.). Food Packaging Shelf. 4: 1-9.

Choi, I. L., T. J. Yoo, H. J. Jung, I. S. Kim, H. M. Kang and Y. B. Lee. 2011. Effects of active modified atmosphere packaging on the storability of fresh-cut Paprika. J. Bio-Environ. Control. 20: 227-232.

Choi, J. H., U. Y. Lee, J. H. Lee, J. J. Choi and J. P. Chun. 2017. Effect of 1-methylcyclopropene on quality of new mid-season Asian pear 'Changjo' during simulated marketing. Korean J. Agric. Sci. 44: 332-338.

Cuadra-Crespo, P. and F. M. del Amor. 2010. Effects of postharvest treatments on fruit quality of sweet pepper at low temperature. J. Sci. Food Agric. 90: 2716-22.

Curl, A. L. 1962. The carotenoids of red bell peppers. J. Agric. Food Chem. 10: 504-509.

Curl, A. L. 1964. The carotenoids of green bell peppers. J. Agric. Food Chem. 12: 522-524.

Di'az-Pe'rez, J. C. 2013. Bell pepper (Capsicum annum L.) crop as affected by shade level: Micro environment, plant growth, leaf gas exchange, and leaf mineral nutrient concentration. Hort Sci. 48: 175-182.

El-Ramady, H. R., É. Domokos-Szabolcsy, N. A. Abdalla, Taha, H. S and M. Fári. 2015. Postharvest management of fruits and vegetables storage. In: Lichtfouse, E. (Ed.), Sustainable Agriculture Reviews. Vol. 15. Springer, New York, pp. 65-152.

Gandolfi, O. R. R., G. R. F. Gonçalves, R. C. F. Bonomo and R. da C. I. Fontan. 2018. Sorption equilibrium and kinetics of thin-layer drying of green bell peppers. Emir. J. Food Agric. 30: 137-143.

Gharezi, M., N. Joshi and E. Sadeghian. 2012. Effect of postharvest treatment on stored cherry tomatoes. J. Nutr. Food Sci. 2: 157.

Hameed, R., A. U. Malik, A. S. Khan, M. Imran, M. Umar and R. Riaz. 2013. Evaluating the effect of different storage conditions on quality of green chillies (Capsicum annuum L.). Trop. Agric. Res. 24: 391-399.

Ilić, Z. S., R. Trajković, Y. Perzelan, S. Alkalai-Tuvia and E. Fallik. 2012. Influence of 1-methylcyclopropene (1-MCP) on postharvest storage quality in green bell pepper fruit. Food Bioproc. Technol. 5: 2758-2767.

Kader, A. A. 1983. Physiological and biochemical effects of carbon monoxide added to controlled atmospheres on fruits. Acta Hortic. 138: 221-226.

Kader, A. A. and R. S. Rolle. 2004. The role of postharvest management in assuring the quality and safety of horticultural produce. FAO Agric. Serv. Bull. 152: 50-51.

Kader, A. A., M. A. Stevens, M. Albright-Holton, L. L. Morris and M. Algazi. 1977. Effect of fruit ripeness when picked on flavor and composition in fresh market tomatoes. J. Am. Soc. Hortic. Sci. 102: 724-731.

Khairi, A. N., M. A. F. Falah, A. Suyantohadi, N. Takahashi and H. Nishina. 2015. Effect of storage temperatures on color of tomato fruit (Solanum lycopersicum Mill.) cultivated under moderate water stress treatment. Agric. Agric. Sci. Proc. 3: 178-183.

Lahay, M., F. Devauxa, M. Poole, B. Seymour and M. Causse. 2013. Pericarp tissue microstructure and cell wall polysaccharide chemistry are differently affected in lines of tomato with contrasted firmness. J. Postharvest Bio. Technol. 76: 83-90.

Lim, B. S., J. S. Lee, H. J. Park, S. Y. Oh and J. P. Chun. 2016. Effects of ethylene treatment on postharvest quality in kiwi fruit. Korean J. Agric. Sci. 43: 340-345.

Lownds, N. K., M. Banaras and P. W. Bosland. 1993. Relationship between postharvest water loss and physical properties of pepper fruit (Capsicum annuum L.). Hort. Sci. 28: 1182-1184.

Mahmood, A., Y. Hu, J. Tanny and E. A. Asante. 2018. Effects of shading and insect-proof screens on crop microclimate and production: A review of recent advances. Sci. Hort. 241: 241-251.

Maria, S., P. Zapata, S. Castillo, F. Guillen and D. Martinez-Romero. 2010. Antioxidant and nutritive constituents during sweet pepper development and ripening are enhanced by nitrophenolate treatments. J. Food Chem. 118: 497-503.

Marin, A., F. Ferreres, F. Tomas-Barberan and M. Gil. 2004. Characterization and quantitation of antioxidant constituents of sweet pepper (Capsicum annuum L.). J. Agric. Food Chem. 52: 3861-3869.

Matus, Z., J. Deli and J. Szabolcs. 1991. Carotenoid composition of yellow pepper during ripening: Isolation of $\beta$-cryptoxanthin 5 , 6-epoxide. J. Agric. Food Chem. 39: 1907-1914.

Nunes, M. C. N., J. K. Brecht, A. M. M. B Morais and S. A. Sargent. 1995. Physical and chemical quality characteristics of strawberries after storage are reduced by a short delay to cooling. Postharvest Biol. Technol. 6: 17-28.

Nyanjage, M. O., S. P. O. Nyalala, A. O. Illa, B. W. Mugo, A. E. Limbe and E. M. Vulimu. 2005. Extending post-harvest life of sweet pepper (Capsicum annum L. 'California Wonder') with modified atmosphere packaging and storage temperature. Agric. Trop. Subtrop. 38: 28-34.

O’Donoghue, E. M., D. A. Brummell, M. J. McKenzie, D. A. Hunter and R. E. Lill. 2017. Sweet capsicum: Postharvest physiology and technologies. N. Z. J. Crop Hortic. Sci. 46: 269-297.

Paull, R. E. 1999. Effect of temperature and relative humidity on fresh commodity quality. Postharvest Biol. Technol. 15: 263-277.

Ramaswamy, H. S. 2015. Post-harvest technologies of fruits 
and vegetables. Destech Publications, Inc., Pennsylvania, US, pp. 1-10.

Renquist, A. R. and J. B. Reid. 1998. Quality of processing tomato (Lycopersicon esculentum) fruit from four bloom dates in relation to optimal harvest timing. N. Z. J. Crop Hortic. Sci. 26: 61-168.

Satyan, S. H. and M. V. Patwardhan. 1983. Organic acid metabolism during ripening of fruits. Indian J. Biochem. Biophys. 20: 311-4.

Shafiee, M., T. S. Taghavi and M. Babalar. 2010. Addition of salicylic acid to nutrient solution combined with postharvest treatments (hot water, salicylic acid and calcium dipping) improved postharvest fruit quality of strawberry. Sci. Hortic. 124: 40-45.

Shim, J. Y., D. G. Kim, J. T. Park, L. M. Kandpal, S. J. Hong, B. K. Cho and W. H. Lee. 2016. Physicochemical quality changes in Chinese cabbage with storage period and temperature: A review. J. Biosyst. Eng. 41: 373-388.

Sigge, G. O., C. F. Hansmanw and E. Joubert. 2001. Effect of storage conditions, packaging material and metabisulphite treatment on the color of dehydrated green bell peppers (Capsicum Annuum L.). Food Qual 24: 218-205.

Simmons, S. L., P. J. Hofman, A. W. Whiley and S. E. Hetherington. 1997. Effects of Preharvest Calcium Sprays and Fertilizer, Leaf: Fruit Ratios and Water Stress on Mango Fruit Quality. Proceedings of International workshop on Disease Control and Storage Life Extension in Fruit, Chiang Mai, Thailand, pp. 19-26.

Simonne, A. H., E. H. Simonne, R. R. Eitenmiller, H. A. Mills and N. R. Green. 1997. Ascorbic acid and provitamin A contents in unusually colored bell peppers (Capsicum annuum L.). J. Food Comp. Anal. 10: 299-311.

Singh, R., S. K. Giri and N. Kotwaliwale. 2014. Shelf-life enhancement of green bell pepper (Capsicum annuum L.) under active modified atmosphere storage. Food Packaging Shelf. 1: 101-112.

Srinivasa, P. C., K. V. H. Prashanth, N. S. Susheelamma, R. Ravi and R. N. Tharanathan. 2006. Storage studies of tomato and bell pepper using eco-friendly films. J. Sci. Food Agric. 86: 1216-1224.

Tano, K., M. K. Oulé, G. Doyon, R. W. Lencki and J. Arul. 2007. Comparative evaluation of the effect of storage temperature fluctuation on modified atmosphere packages of selected fruit and vegetables. Postharvest Biol. Technol. 46: 212-221.

Thompson, J., M. Cantwell, M. L. Arpaia, A. Kader, C. Crisosto and J. Smilanick. 2001. Effect of cooling delays on fruits and vegetable quality. Perish. Hand. Quart. 105: 2-5.

Tigist, M., T. S. Workneh and K. Woldetsadik. 2013. Effects of variety on the quality of tomato stored under ambient conditions. J. Food Sci. Technol. 50: 477-486.

Topuz, A., H. Feng and M. Kushad. 2009. The effect of drying method and storage on color characteristics of paprika. LWT-Food Sci. Technol. 42: 1667-1673.

Tsegay, D., B. Tesfaye, A. Mohammed, H. Yirga and A. Bayleyegn. 2013. Effects of harvesting stage and storage duration on postharvest quality and shelf life of sweet bell pepper (Capsicum annuum L.) varieties under passive refrigeration system. Int. J. Biotechnol. Mol. Biol. Res. 4: 98-104.

Vanderslice, J. T., D. J. Higgs, J. M. Hayes and G. Block. 1990. Ascorbic acid and dehydroascorbic acid content of food-aseaten. J. Food Compos. Anal. 3: 105-118.

Znidarcic, D., I. I. D. Ban, M. M. Oplanic, L. Karic and T. Pozra. 2010. Influence of postharvest temperatures on physicochemical quality of tomatoes (Lycopersicon esculentum Mill.). J. Food Agric. Environ. 8: 21-25. 